\title{
Erratum to: Development and Evaluation of Quantitative Capillary Electrophoresis with a 4-nL Internal Loop Injector
}

\author{
Bangzan Ling ${ }^{1} \cdot{\text { Yuan } \mathrm{Xu}^{1}}^{1}$ Dong Yao $^{1} \cdot$ Lin Zhang $^{1} \cdot$ Yan Wang $^{1} \cdot{\text { Chao } \text { Yan }^{1}}^{1}$
}

Published online: 4 August 2015

(C) Springer-Verlag Berlin Heidelberg 2015

\section{Erratum to: Chromatographia (2015) 78:543-550 \\ DOI 10.1007/s10337-015-2853-7}

In the original publication, the family and given names of the authors were incorrectly listed in references 16, 17 and 20.

The correct lists of authors for these references are:

16. Kanoatov M, Retif C, Cherney LT, Krylov SN (2012) Anal Chem 84:149-154

17. de Jong S, Krylov SN (2012) Anal Chem 84:453-458

20. Musheev MU, Filiptsev Y, Krylov SN (2010) Anal Chem 82:8692-8695

The online version of the original article can be found under doi:10.1007/s10337-015-2853-7.

Chao Yan

chaoyan@sjtu.edu.cn

1 School of Pharmacy, Shanghai Jiao Tong University, Shanghai 200240, China 